\title{
PERSPECTIVAS DE MERCADO E DESAFIOS DA PRODUÇÃo DO ÁCIDO ITACÔNICO A PARTIR DE BIOMASSA
}

Gabrielle das V. Fraga ${ }^{a}$, Alisson D. S. Ruy ${ }^{a}$, Luiz A. M. Pontes ${ }^{a, *,(1)}$, Leila M. A. Campos ${ }^{\mathrm{b}}$ e Leonardo S. G. Teixeira ${ }^{\mathrm{c}}$

aDepartamento de Engenharia Química, Universidade Federal da Bahia, 40210-630 Salvador - BA, Brasil

${ }^{b}$ Escola de Engenharia, Arquitetura e TI, Universidade Salvador, 41940-560 Salvador - BA, Brasil

'Instituto de Química, Universidade Federal da Bahia, 40170-115 Salvador - BA, Brasil

Recebido em 11/02/2020; aceito em 30/04/2020; publicado na web em 18/06/2020

\begin{abstract}
PERSPECTIVES AND CHALLENGES OF ITACONIC ACID PRODUCTION FROM BIOMASS. Itaconic acid (IA) is a very promising platform molecule due to the possibility of it being used to obtain products such as methyl methacrylate and synthetic latex, with the prospect that its global market will grow at an average annual rate of 2.8\% (CAGR) from 2021 to 2026, exceeding US\$ 116.6 million in sales. The main technological route used to obtain itaconic acid is fermentation using different strains of Aspergillus terreus fungi. The main advancements are related to genetic engineering, as Aspergillus terreus is the most tolerant of the microorganisms employed in the process synthesis and optimization. The main substrate used is glucose (52\%), followed by glycerol (25\%). Among the results presented in this paper, the best production was achieved using Ustilago maydis, with $220 \mathrm{~g} \mathrm{~L}^{-1}$ of IA, yielding $0.33 \mathrm{~g} \mathrm{~g}^{-1}$, using glucose as a carbon source. Moreover, it is necessary to continue optimizing the biological process of IA production, since it is a platform molecule with major economic potential.
\end{abstract}

Keywords: itaconic acid; platform molecule; global market; Aspergillus terreus; microorganism.

\section{INTRODUÇÃO}

O uso de fontes renováveis é de fundamental importância para um desenvolvimento econômico com foco na sustentabilidade. Verifica-se a necessidade de inovações para atender às demandas da sociedade, que tem exigido materiais ecologicamente corretos, com garantia da mesma qualidade dos produtos já utilizados. A biomassa apresenta um grande potencial para produzir, de forma sustentável, vários polímeros e químicos verdes, bem como combustíveis, substituindo os produtos de origem fóssil. ${ }^{1,2}$

Os resíduos de biomassa são fontes de açúcar de baixo custo, quando comparados aos produtos de origem petroquímica não renovável. ${ }^{3,4}$ A biomassa lignocelulósica é um exemplo de matéria-prima com esse potencial, sendo constituída majoritariamente por três polímeros: celulose (hexose), hemicelulose (pentose), lignina e, ${ }^{5} \mathrm{em}$ menores quantidades, extrativos e cinzas. ${ }^{5}$ Esses componentes estão organizados na parede celular de modo que as fibras de celulose se encontram altamente ramificadas e envolvidas com a matriz amorfa de lignina e hemicelulose, conferindo resistência ao acesso de enzimas/ microrganismos (Figura 1)..$^{6-8}$

O ácido itacônico (AI), também conhecido como ácido metileno succínico, é um ácido orgânico dicarboxílico saturado, que foi listado

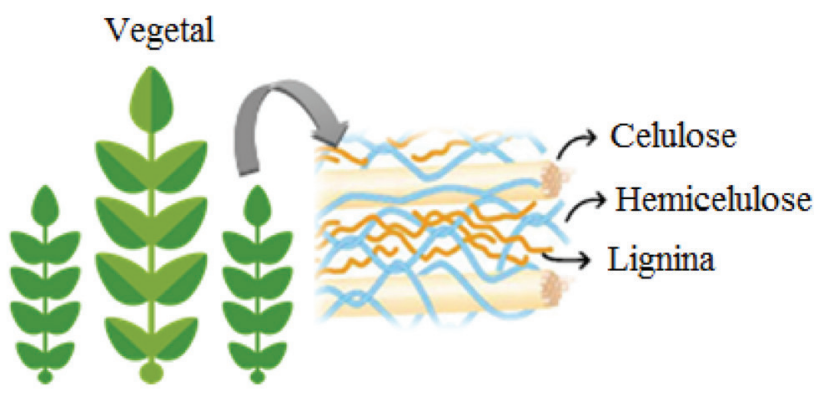

Figura 1. Estrutura do material lignocelulósico

*e-mail: uolpontes@uol.com.br pelo Departamento de Energia dos Estados Unidos (DOE) como uma das doze potenciais moléculas-plataformas. Essas moléculas apresentam vários grupos funcionais que servem de base para a produção de novas moléculas de grande interesse para a indústria, que podem ser obtidas a partir da biomassa..$^{9,10}$

O AI pode ser utilizado como monômero na síntese do metacrilato de metila (MMA) e resinas acrílicas, além de integrar compostos que servem de base para a indústria farmacêutica e agrícola. ${ }^{11,12}$ Possui química semelhante ao anidrido maleico, produzido na petroquímica, podendo ser substituto na obtenção do 1,4-butanodiol (BDO), tetraidrofurano (THF), precursor de biocombustíveis, gamabutirolactona (GBL), itaconato de di-n-butila e itaconato de dimetila, diésteres e sais metálicos com grande valor comercial. ${ }^{13,14}$

Seu mercado está concentrado nas regiões Ásia-Pacífico, Europa e América do Norte, onde há contínuo investimento na melhoria da seletividade e no rendimento do processo bioquímico, visando competir na substituição, por exemplo, do anidrido maleico. ${ }^{15} \mathrm{O}$ desafio está no desenvolvimento da engenharia genética e novas tecnologias de processos fermentativos que possam viabilizar sua produção industrial. ${ }^{12}$ Percebe-se, também, que são necessários estudos de novas matérias-primas de cunho sustentável na sua síntese. ${ }^{16}$

Nesse contexto, esse trabalho teve como objetivo fazer um levantamento das tecnologias envolvendo o processo de biossíntese do AI a partir de biomassa, baseado na avaliação de artigos científicos e patentes publicados, estabelecendo uma análise crítica a respeito destas tecnologias, bem como suas perspectivas de produção para os próximos anos.

\section{Características e histórico da produção e do ácido itacônico}

O AI é um ácido orgânico dicarboxílico saturado, também chamado de ácido succínico de metileno. Apresenta fórmula molecular $\mathrm{C}_{5} \mathrm{H}_{6} \mathrm{O}_{4}$, cuja estrutura possui um grupo carboxílico em cada extremidade, ${ }^{17}$ a qual the confere a vantagem de realizar reações de polimerização (Figura 2). Propriedades físico-químicas do AI estão apresentadas na Tabela $1 . .^{18,19}$ 


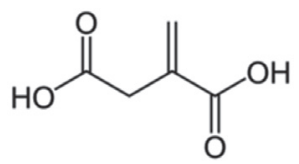

Figura 2. Estrutura molecular do ácido itacônico

Tabela 1. Propriedades físico-químicas do ácido itacônico

\begin{tabular}{lc}
\hline Propriedades & Valores associados \\
\hline Massa molar & $130,1 \mathrm{~g} \mathrm{~mol}^{-1}$ \\
Ponto de fusão & $165-168^{\circ} \mathrm{C}$ \\
Ponto de ebulição & $268^{\circ} \mathrm{C}$ \\
Densidade & $1,632 \mathrm{~g} \mathrm{~L}^{-1}\left(20^{\circ} \mathrm{C}\right)$ \\
Solubilidade em $\mathrm{H}_{2} \mathrm{O}$ & $83,1 \mathrm{~g} \mathrm{~L}^{-1}$ \\
\hline
\end{tabular}

Inicialmente, o AI foi sintetizado por Baup, em 1837, a partir da termodecomposição do ácido cítrico, transformado-o em anidrido itacônico, seguida pela hidrólise do anidrido (Figura 3). ${ }^{3,19} \mathrm{O}$ processo químico se mostrou ineficiente e economicamente inviável do ponto de vista industrial sendo substituído por rotas biotecnológicas.

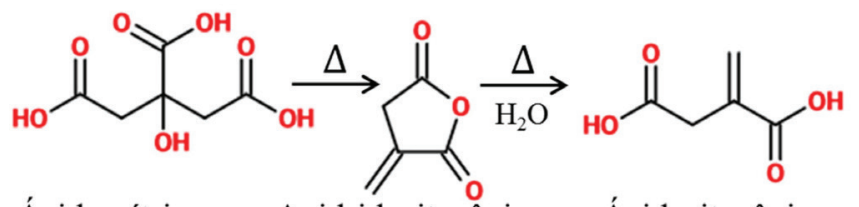

Ácido cítrico Anidrido itacônico

Ácido itacônico

Figura 3. Reação de obtenção do ácido itacônico

Posteriormente, em 1932, Kinoshita apresentou a síntese biológica do AI empregando o fungo osmofílico Aspergillus itaconicus. Em 1939, Calam, Oxford \& Raistrick utilizaram o A. terreus e verificaram uma maior capacidade de produção do que o A. itaconicus. ${ }^{19-21} \mathrm{Em}$ 1945, Lockwood e Ward realizaram testes com 308 cepas e identificaram o A. terreus NRRL 1960 como uma alternativa promissora. ${ }^{22}$

$\mathrm{O}$ interesse crescente por sustentabilidade, conservação ambiental, recursos renováveis e menores custos associados ao consumo de energia, a partir dos anos 80, levou ao desenvolvimento da fermentação descontínua e contínua avançadas, empregando tecnologias e estratégias de desenvolvimento de bioprocessos para melhorar a produção de $\mathrm{AI} .^{23}$

Considerando a possibilidade de se trabalhar com diferentes fungos, de modo a aumentar o rendimento da etapa fermentativa, foram testados o Aspergillus itaconicus, fungos filamentosos, como o Ustilago maydis, ${ }^{24,25}$ além de estirpes mutantes de Candida. ${ }^{26}$ Apesar da grande variedade de microrganismos, atualmente, o Aspergillus terreus, utilizando glicose ou melaço pré-tratado como substrato, tem sido o mais eficiente nos processos industriais de produção do AI..$^{27,28}$

\section{Potencial de mercado do ácido itacônico}

Estima-se que o mercado do ácido itacônico em 2020 seja equivalente a US\$ 96 milhões, tendo como projeção US\$116,6 milhões até 2026, com taxa de crescimento anual composta (CAGR) de 2,8\% (2021-2026). ${ }^{29}$ As fabricações de polímeros, como o MMA, formado a partir da reação de descarboxilação; látex sintético (SBR), pela copolimerização com estireno e butadieno; e resina de poliéster insaturado (UPR), através da poliesterificação, são suas principais aplicações. $\mathrm{O}$ AI pode substituir outros ácidos insaturados e anidridos, tais como os ácidos acrílico, maleico, fumárico, metacrílico e seus derivados. ${ }^{30}$
A produção e o consumo estão concentrados na China, Japão, Coreia, Austrália, Inglaterra, Alemanha, Rússia, Itália, EUA, Canadá e México. ${ }^{31}$ Os países asiáticos representam o maior mercado e competitividade mundial. Os países europeus apresentam um crescimento lento, devido a regulações governamentais. Os EUA são o segundo maior mercado, após a China, com incremento no desenvolvimento de novas tecnologias no setor industrial, em particular, nos segmentos de detergentes; látex sintético, usado em pneus; e MMA, que é utilizado em revestimentos, plásticos transparentes e adesivos. ${ }^{32}$

As principais empresas produtoras de AI são a Itaconix Corporation, Qingdao Langyatai Group Co., Ltd., Zhejiang Guoguang Biochemistry Co., Ltd., Jinan Huaming Biochemistry Co. Ltd., Iwata Chemical Co., Ltd., Alpha Chemika e Shandong Kaison Biochemical Co. ${ }^{33}$

O custo de produção (entre 1,7 a 2,0 US $\$ \mathrm{~kg}^{-1}$ ) é o principal fator que dificulta a ampliação do seu mercado, ${ }^{34}$ pois, atualmente, é mais elevado do que o de seus similares, como o anidrido maleico. Para ser competitivo com commodities análogas, o custo com a fermentação do AI precisa alcançar US\$ $0,5 \mathrm{~kg}^{-1} \cdot{ }^{35}$ Atualmente, o AI já é competitivo com o ácido acrílico e pode, em futuro próximo, substituir o anidrido maleico e o ácido fumárico com melhorias nas tecnologias de fermentação e uso de processos de separação, tais como a adsorção, na etapa de purificação. ${ }^{30,34}$

\section{Levantamento de patentes e artigos sobre o ácido itacônico}

A análise do desenvolvimento das rotas tecnológicas para a produção do AI, ao longo dos anos, foi baseada na coleta de dados de patentes (1963-2019) e artigos (1945-2019). A ferramenta utilizada para a seleção dos artigos científicos foi a Web of Science (www. webofscience). As patentes foram obtidas através da base de dados Derwent Innovations Index (www.derwentinnovationsindex.com).

Os bancos de dados retornaram com 1.412 depósitos de patentes (1963-2019) e 879 publicações científicas (1945-2019). Conforme pode ser observado na Figura 4a, a partir do período 2006-2010, verificou-se um aumento mais significativo do número de patentes e artigos científicos publicados. Esse fato pode estar relacionado ao interesse na busca de processos tecnológicos envolvendo fontes renováveis para produção do AI, como molécula plataforma, em substituição a obtenção de produtos de origem fósseis.

Foi realizada, então, uma nova busca, utilizando as mesmas bases de dados, porém, ampliando as palavras-chave (itaconic, itaconic acid, Aspergillus, production, fermentation) que, combinadas, restringiram os resultados às informações que se desejavam obter. $\mathrm{Na}$ Figura 4b, são mostrados os percentuais dos resultados para artigos científicos e patentes referentes à rota bioquímica de produção do AI, identificados de acordo com a inovação proposta, ou seja, o tipo de microrganismo (desenvolvimento de novas cepas e alterações nos seus genes a partir da engenharia genética), substrato (fontes de biomassa) e o processo de produção (reatores air-lift (ARL), tanque agitado (STR) e contínuo).

Para o tipo de microrganismo, foram mapeados os fungos mais utilizados na produção de AI. Pode-se constatar que o principal fungo, representando $58 \%$ das publicações, foi o Aspergillus terreus, seguido da Escherichia coli (21\%), Ustilago maydis (10\%), Aspergillus niger (7\%) e Pseudozyma antarctica (5\%). A maior parte das publicações está relacionada à modificações genéticas, voltadas para o desenvolvimento de microrganismos mais resistentes ao processo fermentativo, que potencializam as plataformas microbianas conferindo um caráter mais robusto, com elevada capacidade de transportar oxigênio e suportar impurezas do meio reacional.

A glicose tem sido a substância mais utilizada no processo fermentativo como substrato de partida, aparecendo em $52 \%$ dos resultados da busca, seguida do glicerol (25\%), amido (15\%), xilose 


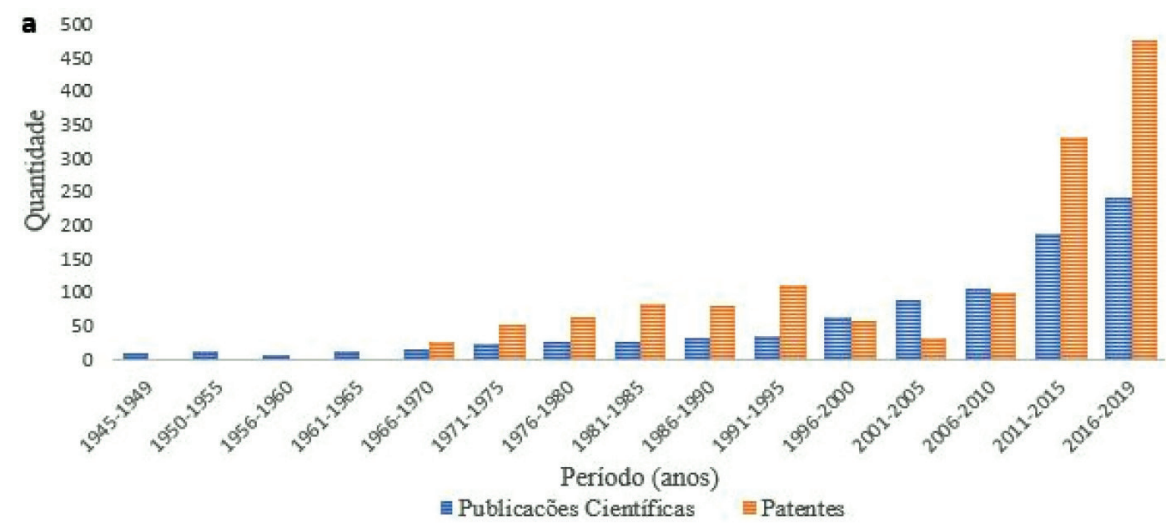

b
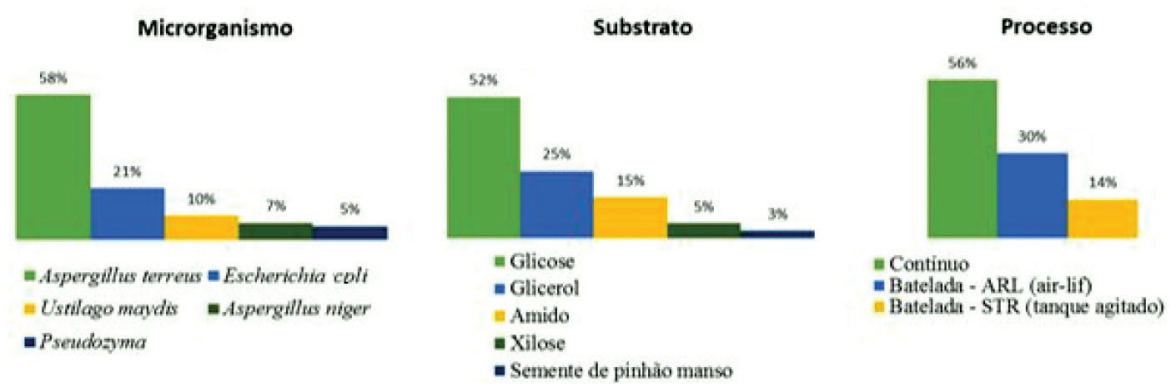

Figura 4. a) Número de publicações científicas e patentes selecionadas a partir dos bancos de dados Web of Science e Derwent Index, utilizando no campo de busca a palavra-chave "itaconic acid". b) Percentuais de publicações científicas e patentes referentes a rota bioquímica de produção do ácido itacônico quanto ao tipo de microrganismo, substrato e processo

(5\%) e pinhão manso (3\%). A glicose possui um maior fluxo metabólico na geração do piruvato, através da glicólise, apresentando os melhores resultados durante a fermentação. Quanto aos demais substratos, verifica-se um menor número de publicações em virtude, possivelmente, da menor disponibilidade da biomassa lignocelulósica, apesar de alguns dos resultados de rendimento em AI serem próximos aos obtidos com a utilização da glicose.

Com relação ao tipo de processo, a fermentação contínua destaca-se como o principal método utilizado, representada por $56 \%$ dos resultados da busca. Esse tipo de processo apresenta como uma das vantagens a possibilidade de substituição contínua do meio de cultura, amenizando a geração de inibidores durante o processo reacional da fermentação.

\section{Tecnologias para a síntese do ácido itacônico}

A produção do ácido itacônico ocorre a partir de rotas biológicas. As variáveis críticas do processo de fermentação são o pH, aeração, separação dos produtos e escolha da matéria-prima, fonte de carbono. $\mathrm{O}$ pH afeta a taxa de produção de AI, e deve se situar entre 2 e 3 . O estresse hidromecânico, a que o fungo é submetido durante a aeração e a distribuição homogênea do oxigênio gasoso, está diretamente relacionado ao crescimento do microrganismo. ${ }^{36,37} \mathrm{O}$ custo da separação a jusante da fermentação (que tem impacto em mais de $30 \%$ do custo de produção) e a escolha da matéria-prima renovável e de baixo custo são desafios a serem superados.

Na Figura 5, um esquema da via metabólica de produção do ácido itacônico é apresentado.

O mecanismo para a biossíntese do AI ocorre a partir da transformação de açúcares em piruvato por intermédio do processo de oxidação a cis-aconitato no Ciclo de Krebs ou no Ciclo dos Ácidos Tricarboxílicos (TCA) ${ }^{38,39} \mathrm{O}$ cis-aconitato é o iniciador mais utilizado, e é sintetizado a partir da condensação da acetil-CoA e do oxaloacetato para gerar o citrato com subsequente desidratação a cis-aconitato. ${ }^{40}$
A enzima utilizada nesse processo é o cis-aconitato descarboxilase (CAD), que remove a carboxila do ácido cis-aconitato a AI. ${ }^{41}$

Na Tabela 2 é mostrada uma relação dos principais microrganismos utilizados na síntese do AI, suas respectivas produções e substratos utilizados. $^{42-82}$

Verifica-se que há diversos microrganismos sendo testados em laboratório para a produção do AI. Cada um apresenta vantagens e desvantagens que devem ser consideradas na análise do melhor sistema a ser usado, visando aplicação em uma planta industrial. Dentre os microrganismos utilizados no processo de biossíntese do AI, destacam-se o Ustilago maydis, a Escherichia coli, a Pseudozyma antarctica, o Aspergillus niger e o Aspergillus terreus.

$\mathrm{O}$ A. terreus é o microrganismo mais utilizado e possui boa resistência a impurezas. ${ }^{42}$ Sua produtividade depende fortemente da aeração no biorreator, uma vez que as células do fungo crescem na forma de pellets que formam uma barreira de transferência de massa no biorreator, prejudicando a difusão do oxigênio do ar. ${ }^{19}$ Esse problema pode ser minimizado com a injeção de ar enriquecido com oxigênio no sistema.

A partir de modificações genéticas e uso de diferentes substratos durante a etapa fermentativa, foram obtidos diversos resultados que variam em uma larga faixa de produção de AI. Verifica-se uma tentativa de potencializar a etapa fermentativa utilizando o Aspergillus terreus, através de modificações genéticas, a exemplo da superexpressão dos principais genes relacionados - cadA (cis-aconitato descarboxilase), mttA (fator de determinação da transcrição mitocondrial) e mfsA (transporte de plasma) -, que influenciam diretamente na concentração de AI (Figura 6). ${ }^{14,36}$

O melhor resultado para o Aspergillus terreus, individualmente, foi encontrado para a cepa DSM 23081. Foram obtidos $160 \mathrm{~g} \mathrm{~L}^{-1} \mathrm{de} \mathrm{AI}$, com rendimento de $0,58 \mathrm{~g} \mathrm{~g}^{-1}$, utilizando a glicose como substrato. ${ }^{61}$

$\mathrm{O}$ uso do Aspergillus niger tem uma longa tradição na produção de celulase, pectinase, entre outras enzimas, e ácidos orgânicos, sendo amplamente utilizado na biotecnologia. A eficiência da biossíntese do 


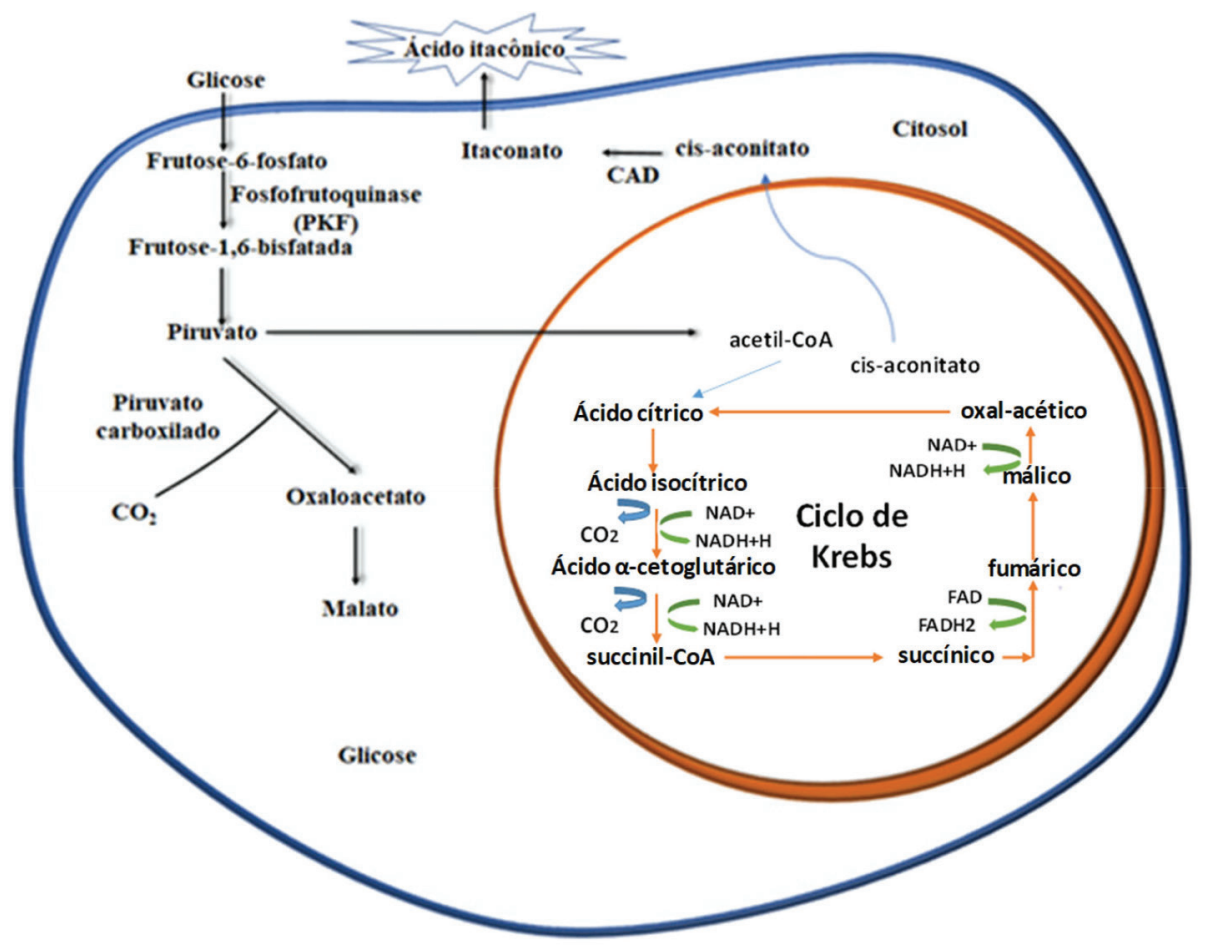

Figura 5. Esquema da via metabólica para a biossíntese do ácido itacônico. Adaptado da ref. 22
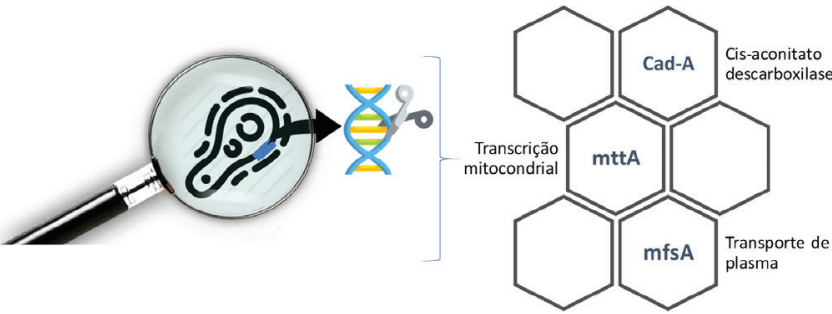

Figura 6. Principais modificações genéticas no microrganismo Aspergillus terreus

AI utilizando essa plataforma microbiana é baixa, quando comparada com os valores de produção do ácido cítrico, oxálico ou glucônico. $\mathrm{Na}$ tentativa de maximizar a produção do AI, a engenharia genética tem buscado direcionar esforços na expressão heteróloga (expressão de um gene, ou parte dele, no microrganismo hospedeiro) do cisaconitato descarboxilase durante o ciclo de Krebs. ${ }^{83}$

A melhor produção de AI usando o Aspergillus niger foi de $29,2 \mathrm{~g} \mathrm{~L}^{-1}$, empregando a glicose como substrato. ${ }^{70}$ Verifica-se que esse resultado é $82 \%$ inferior em relação ao melhor resultado reportado com o A. terreus DSM 23081 (160 $\left.\mathrm{g} \mathrm{L}^{-1}\right){ }^{61}$ Os autores propuseram a investigação do transcriptoma (reflexo direto da expressão dos genes) do A. niger visando potencializar a biossíntese do AI através de alterações genéticas, por meio da ação de itaconil-CoA transferase (IctA), itaconil-CoA hidratase (IchA) e citramailil-CoA liase, mesma rota identificada para o A. terreus. ${ }^{70}$

Ao se utilizar o microrganismo U. maydis e glicose como substrato, obteve-se uma boa produção de $\mathrm{AI}\left(53,5 \mathrm{~g} \mathrm{~L}^{-1}\right)$, alcançando um rendimento de $0,47 \mathrm{~g} \mathrm{~g}^{-1} .^{74}$ Esse valor é inferior quando comparado aos resultados utilizando o A. terreus. Uma vantagem do $U$. maydis reside no fato de que, apesar de ser um fungo filamentoso, sua morfologia é semelhante à de leveduras (basidiomiceto), o que facilita a transferência de oxigênio, além de apresentar baixa viscosidade, baixa sensibilidade ao estresse hidromecânico e rápido crescimento no meio reacional.

A melhor produção do U. maydis foi de $220 \mathrm{~g} \mathrm{~L}^{-1}$ de AI, com rendimento de $0,48 \mathrm{~g} \mathrm{~g}^{-1}$, utilizando a glicose como fonte de carbono. ${ }^{75}$ Esse aumento significativo da produção de AI foi devido à geração de diferentes cepas hiper produtoras de itaconato, utilizando os genomas CRISPR/Cas9 e FLP/FRT, ferramentas de edição para exclusão de genes, substituição de promotores e superexpressão de genes, que relacionados com a morfologia e patologia do fungo, impactam diretamente no seu crescimento durante a etapa fermentativa. ${ }^{75}$

Outro exemplo do uso da engenharia genética para otimizar a produção de AI pode ser dado com o E. coli, considerando que, quando comparado aos demais fungos, esse microrganismo apresenta maior acessibilidade e facilidade quanto à manipulação dos genes e um crescimento celular mais rápido. Ao se utilizar o microrganismo $E$. coli modificado, com a incorporação dos genes cadA do Aspergillus terreus e gltA (Corynebacterium glutamicum), o melhor resultado obtido foi $32 \mathrm{~g} \mathrm{~L}^{-1}$ de AI, com rendimento de $0,68 \mathrm{~mol} \mathrm{~mol}^{-1}$, utilizando a glicose como fonte de carbono. ${ }^{79} \mathrm{~A}$ E. coli apresenta grande potencial na produção de AI, devido a sua flexibilidade metabólica. Entretanto, o excesso de substrato no meio reacional, direciona a biossíntese para a rota do oxaloacetato formando acetato, um subproduto da reação, e minimiza a formação de hidroximetilfurfural (HMF) e furfural. ${ }^{80}$

Com a Pseudozyma antarctica NRRL Y-7808, obteve-se produção de $30 \mathrm{~g} \mathrm{~L}^{-1}$ de AI, utilizando no processo fermentativo quantidades reduzidas de nitrogênio, com a finalidade de induzir melhorias no processo de produção do AI e minimizar a formação de inibidores. ${ }^{82}$

Em relação ao substrato, a glicose é a mais usada; entretanto, seu custo e disponibilidade é uma desvantagem. O substrato é importante do ponto de vista econômico levando em conta a competitividade do processo. Alguns autores vêm trabalhando com resíduos de biomassa que, embora tenham baixos custos, necessitam de etapas de prétratamento para que possam atingir produção competitiva.

$\mathrm{O}$ uso da palha de trigo como substrato resultou em um rendimento de $0,41 \mathrm{~g} \mathrm{~g} \mathrm{~g}^{-1} \cdot{ }^{60}$ Os autores fizeram o pré-tratamento da matéria-prima seguido da sacarificação, a fim de determinar a concentração dos açúcares presentes no hidrolisado. A partir dessa informação, os autores prepararam um hidrolisado da palha de trigo artificial na mesma concentração e quantidade de monossacarídeos 
Tabela 2. Microrganismos e substratos usados na produção de ácido itacônico

\begin{tabular}{|c|c|c|c|c|c|}
\hline \multicolumn{2}{|l|}{ Microrganismo / cepa } & Substrato & Produção, $\mathrm{g} \mathrm{L}^{-1}$ & Rendimento, $\mathrm{g} \mathrm{g}^{-1}$ & Ref \\
\hline & \multirow{4}{*}{ NRRL 1960} & \multirow{4}{*}{ Glicose } & 87,32 & NA & 42 \\
\hline & & & 49,5 & 0,41 & 43 \\
\hline & & & 23,2 & NA & 44 \\
\hline & & & 51,9 & NA & 45 \\
\hline & \multirow{8}{*}{ NRRL 1960} & Xilose & 35,2 & NA & \multirow{3}{*}{45} \\
\hline & & Arabinose & 32,1 & NA & \\
\hline & & Glicose, xilose e arabinose & 30,8 & NA & \\
\hline & & \multirow{5}{*}{ Glicose } & 73,6 & NA & 46 \\
\hline & & & NA & 0,31 & 47 \\
\hline & & & 60 & NA & 48 \\
\hline & & & NA & 0,21 & 49 \\
\hline & & & 50 & 0,41 & 50 \\
\hline & NRRL 1972 & Glicose & 40,7 & NA & 51 \\
\hline & M69 & Ácido acético & 33,6 & 0,56 & 52 \\
\hline & TN-484 & Amido de milho & 60 & NA & 53 \\
\hline & ATCC 10020 & Casca de arroz & 1,9 & $4,9 \cdot 10^{-3}$ & 54 \\
\hline \multirow[t]{17}{*}{ Aspergillus terreus } & $\mathrm{C} 1$ & Amido de batata & 30,8 & 0,35 & \multirow{2}{*}{55} \\
\hline & $\mathrm{C} 2$ & Amido de batata & 23,4 & 0,34 & \\
\hline & \multirow{2}{*}{ SKR10 } & Amido de milho, maçã e banana & 20 & NA & \multirow{2}{*}{56} \\
\hline & & Amido de milho & 31 & & \\
\hline & \multirow{4}{*}{ NRRL 1961} & Glicose & 49,8 & \multirow{4}{*}{ NA } & \multirow{4}{*}{57} \\
\hline & & Xilose & 38,9 & & \\
\hline & & Arabinose & 34,8 & & \\
\hline & & Glicose, xilose e arabinose & 33,2 & & \\
\hline & \multirow{5}{*}{ DSM 23081} & \multirow{2}{*}{ Glicose } & 86,2 & 0,62 & 58 \\
\hline & & & 146 & 0,58 & 59 \\
\hline & & Palha de trigo & 27,7 & 0,41 & 60 \\
\hline & & (1: & 160 & 0,58 & 61 \\
\hline & & Glicose & 105 & NA & 62 \\
\hline & A729 & Glicose & 45,5 & NA & 63 \\
\hline & \multirow{3}{*}{-} & \multirow{2}{*}{ Semente de pinhão manso } & 24,45 & NA & 64 \\
\hline & & & 48,7 & NA & 65 \\
\hline & & Glicerol & 26,9 & NA & 66 \\
\hline \multirow{6}{*}{ Aspergillus niger } & & \multirow{4}{*}{ Glicose } & 26,2 & NA & 67 \\
\hline & & & 2,0 & NA & 68 \\
\hline & & & 4,92 & NA & 69 \\
\hline & & & 29,2 & 0,37 & 70 \\
\hline & & Sorbitol & 8 & NA & 71 \\
\hline & & Sorbitol e xilose & 7,1 & NA & 72 \\
\hline \multirow{4}{*}{ Ustilago maydis } & & \multirow{3}{*}{ Glicose } & 4 & NA & 73 \\
\hline & & & 53,5 & 0,47 & 74 \\
\hline & & & 220 & 0,48 & 75 \\
\hline & & Celulobiose & 5,0 & NA & 76 \\
\hline Ustilago vetiveriae TZI & & Glicerol & 34,7 & 0,18 & 77 \\
\hline$E_{0}$ & & $C 1:-20$ & 0,34 & NA & 78 \\
\hline Eschericnia coin & & Gilcose & 32 & 0,49 & 79 \\
\hline 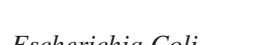 & & Glicose & 5,7 & 0,62 & 80 \\
\hline Escherichia Coll & & Acetato & 3,57 & 0,32 & 81 \\
\hline Pseudozyma antartica & & Glicose & 30 & 0,37 & 82 \\
\hline
\end{tabular}

$\mathrm{g} \mathrm{L}^{-1}$ : grama de itaconato por litro de substrato; $\mathrm{g} \mathrm{g}^{-1}$ : grama de itaconato por grama de substrato; NA: não informado no artigo. 


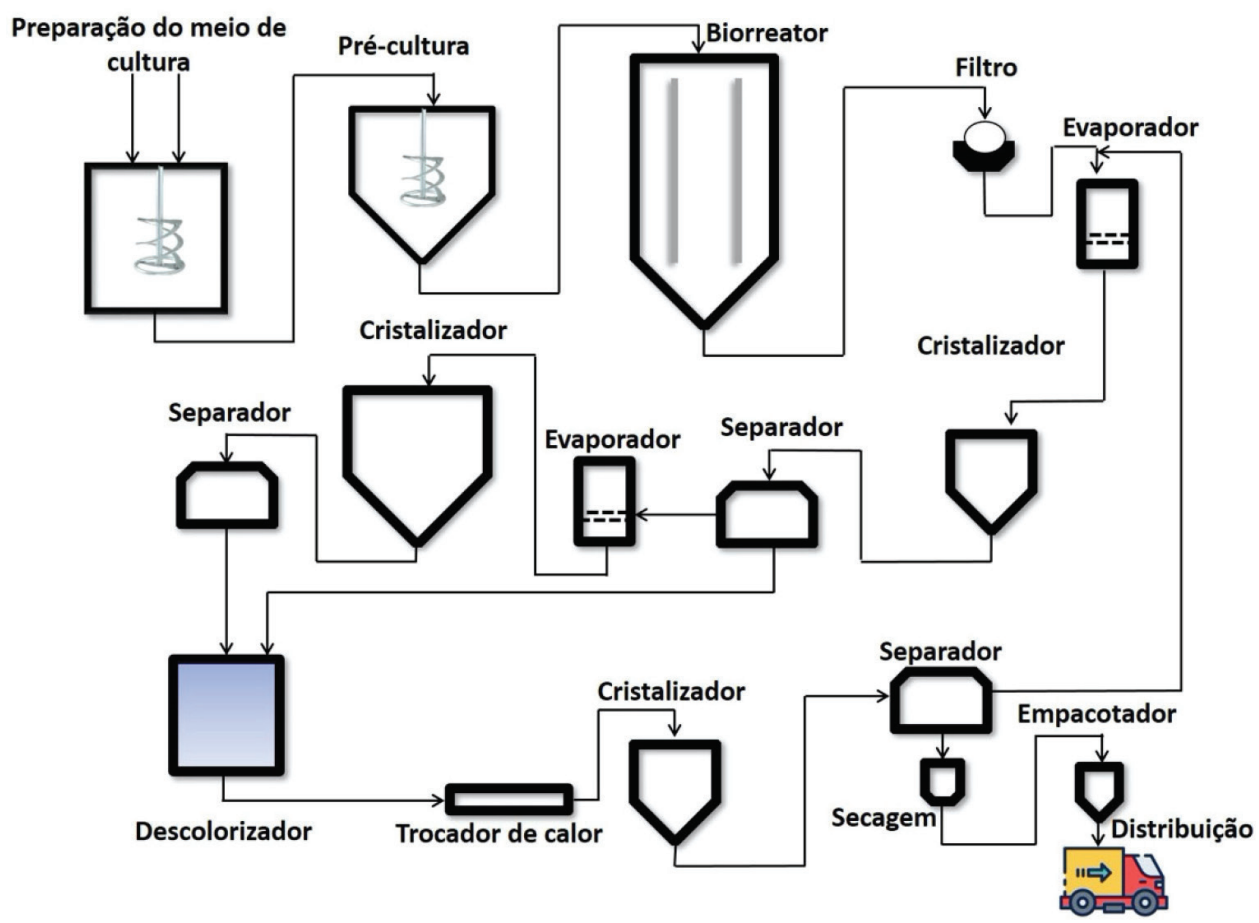

Figura 7. Diagrama esquemático do processo de produção do ácido itacônico. Adaptado da ref. 22

que o hidrolisado real. ${ }^{60}$ Furfural e HMF foram responsáveis por minimizarem as atividades de enzimas intracelulares, como o piruvato, resultando em um menor fluxo de acetil-CoA no TCA, impactando de forma negativa na produção de AI.

O uso de hidrolisado artificial pode ser considerado uma estratégia para a potencialização da produção do AI, uma vez que os valores, quando comparados com o substrato bruto, mostram que o rendimento aumentou de $0,27 \mathrm{~g} \mathrm{~g}^{-1}$ para $0,41 \mathrm{~g} \mathrm{~g}^{-1}$, cerca de $51,82 \%$, e produção de $23,3 \mathrm{~g} \mathrm{~L}^{-1}$ para $27,7 \mathrm{~g} \mathrm{~L}^{-1}$, o equivalente a $18,88 \% .{ }^{60}$

\section{Produção industrial do ácido itacônico}

A biossíntese do AI pode ser desenvolvida em uma biorrefinaria, unidade industrial que integra processos e equipamentos de conversão de biomassa e seus resíduos, responsável pelos novos processos de transformação, onde espera-se que os produtos resultantes sejam altamente rentáveis. ${ }^{84,85}$

Na produção industrial do AI, são necessárias 6 etapas: filtração, fermentação, descoloração, purificação, secagem e empacotamento. Além disso, caso se deseje um aumento da pureza do ácido, etapas de purificação, como extração por solvente, troca iônica e re-descoloração, podem ser repetidas o quanto for necessário. ${ }^{3}$ Na Figura 7 , é mostrado o diagrama referente ao processo de produção do AI, no qual, após as etapas de preparação da cultura, o caldo segue para a etapa de filtração com a finalidade de reter micélios e sólidos em suspensão, resultantes do processo fermentativo. Posteriormente, ocorre o processo duplo de cristalização por resfriamento até $15^{\circ} \mathrm{C}$. $\mathrm{O}$ caldo resultante passa por um trocador de calor, recristalizado, seco e empacotado para ser distribuído.

Tratando-se da produção industrial do AI, a fermentação ocorre em batelada (fermentação descontínua), em reatores do tipo air-lift (ARL) ou, em reator de tanque agitado (STR). Para um reator STR, a produtividade máxima foi de $0,48 \mathrm{~g} \mathrm{~L}^{-1} \mathrm{~h}^{-1}$ de AI. Já com o ARL, a taxa aumentou para $0,64 \mathrm{~g} \mathrm{~L}^{-1} \mathrm{~h}^{-1}$, com alimentação de $\mathrm{O}_{2}$ a $0,41 \mathrm{~L}$ $\min ^{-1}{ }^{86}$ Com relação à fermentação do AI, o ARL melhora a produção quando comparada com a do STR, e diminui o cisalhamento, responsável por provocar alterações morfológicas irreversíveis no fungo, prejudicando o processo produtivo.$^{87,88} \mathrm{O}$ efeito da agitação deve ser avaliado e tratado de forma criteriosa, uma vez que irá afetar a estrutura morfológica do fungo. O impelidor mais adequado é do tipo "orelha de elefante", pois além de amenizar o cisalhamento, apresenta baixo consumo de energia durante o cultivo das células. ${ }^{89}$

A produção industrial em reator contínuo tem como vantagem a minimização da formação de inibidores durante o processo reacional, por ocorrer substituição contínua do meio de cultura. Verifica-se nesse sistema uma produtividade de AI quatro vezes maior $\left(1,2 \mathrm{~g} \mathrm{~L}^{-1} \mathrm{~h}^{-1}\right)$ em relação à fermentação descontínua $\left(0,3 \mathrm{~g} \mathrm{~L}^{-1} \mathrm{~h}^{-1}\right) .{ }^{90}$

\section{CONCLUSÕES}

O ácido itacônico é uma molécula plataforma de interesse para ser produzida em uma biorrefinaria, agregando valor ao sistema. A diversidade de substratos que podem ser utilizados é uma vantagem, mas a glicose tem sido o substrato mais utilizado na produção de AI. O uso de resíduos de biomassa pode melhorar a competitividade do processo de produção do AI devido ao baixo custo da matéria-prima. Entretanto, as etapas de pré-tratamento e hidrólise ainda precisam de desenvolvimento tecnológico para que tenha viabilidade econômica. $\mathrm{O}$ custo de produção de pelo menos $1,7 \mathrm{US} \$ \mathrm{~kg}^{-1}$ é o fator que mais dificulta a ampliação do seu mercado. Atualmente, o AI é produzido industrialmente utilizando o microrganismo A. terreus com modificações em seus genes, em virtude de apresentar as maiores taxas de produção. Entretanto, o fungo filamentoso U. maydis, MB215 surge com boa expectativa, considerando o potencial de produção de $220 \mathrm{~g} \mathrm{~L}^{-1}$. O principal desafio tecnológico reside na obtenção de cepas geneticamente modificadas, com diferenciação celular em um mesmo microrganismo, superexpressão dos principais genes relacionados a produção do AI, que influenciam a eficiência da etapa fermentativa.

\section{AGRADECIMENTOS}

O presente trabalho foi realizado com apoio da Coordenação de Aperfeiçoamento de Pessoal de Nível Superior - Brasil (CAPES) - Código de Financiamento 001. Os autores agradecem também 
os apoios recebidos do Conselho Nacional de Desenvolvimento Científico e Tecnológico (CNPq) e da Fundação de Amparo à Pesquisa do Estado da Bahia (FAPESB).

\section{REFERÊNCIAS}

1. Bafana, R.; Pandey, R. A.; Crit. Rev. Biotechnol. 2017, 38, 68.

2. Galembeck, F.; Barbosa, C. A. S.; Souza, R. A.; Quim. Nova 2009, 32, 571.

3. Teleky, B.-E.; Vodnar, D. C.; Polymers 2019, 11, 1035.

4. Ferreira, V. F.; Silva, F. C.; Quim. Nova 2013, 36, 1514

5. Vaz Júnior, S.; Soares, I. P.; Ferreira, P. G.; Quim. Nova 2014, 37, 709.

6. Luo, Y.; Zheng, L.; Xiaoling, L.; Xiaofeng, L.; Fan, J.; Clark, J. H.; Hu, C.; Catal. Today 2019, 319, 14.

7. Moura, H. O. M. A.; Campos, L. M. A.; Da Silva, V. L.; De Andrade, J. C. F.; De Assumpção, S. M. N.; Pontes, L. A. M.; Carvalho, L. S.; Cellulose 2018, 25, 5669.

8. Guerra, G. N.; Albuquerque, E. C. M. C; Campos, L. M. A.; Pontes, L. A. M.; J. Nat. Fibers 2019, 16, 1.

9. Rodrigues, J. A. R.; Quim. Nova 2011, 34, 1242.

10. Werpy, T.; Petersen, G.; Department of Energy, Energy Efficiency and Renewable Energy: Washington, DC, USA, 2004; Volume I 2004.

11. Hedge, K.; Prabhu, A.; Sarma, S. J., Brar, S. K.; Dasu, V. V. Em Platform Chemical Biorefinery: Future Green Chemistry, Brar, S. K.; Sarma, S. J.; Pakshirajan, K., eds.; Elsevier: Amsterdam, 2016, cap. 10.

12. Nieder-Heitmann, M.; Haigh, K. F.; Görgens, J. F.; Bioresour. Technol. 2018, 262, 159.

13. Magalhães Júnior, A. I.; De Carvalho, J. C.; Medina, J. D. C.; Soccol, C. R.; Appl. Microbiol. Biotechnol. 2016, 101, 1.

14. Saha, B. C.; J. Ind. Microbiol. Biotechnol. 2017, 44, 303.

15. El-Imam, A. A.; Du, C.; J. Biodivers. Biopros. Dev. 2014, 1, 119.

16. Regestein, L.; Klement, T.; Grande, P.; Kreyenschulte, D.; Heyman, B.; Maßmann, T.; Eggert, A.; Sengpiel, R.; Wang, Y.; Wierckx, N.; Blank, L. M.; Spiess, A.; Leitner, W.; Bolm, C.; Wessling, M.; Jupke, A.; Rosenbaum, M.; Büchs, J.; Biotechnol. Biofuels 2018, 11, 279.

17. Hejian, H.; Yusoff, M. W.; Curr. Res. J. Biol. Sci. 2015, 2, 37.

18. Klement, T.; Milker, S.; Jäger, G.; Grande, P. M.; Domínguez, M. P.; Bünches, J.; Microb. Cell Fact. 2012, 11, 43.

19. Kuenz, A.; Krull, S.; Appl. Microbiol. Biotechnol. 2018, 102, 3901.

20. Willke, T.; Vorlop, KD.; Appl. Microbiol. Biotechnol. 2001, 56, 289.

21. Klement, T.; Büchs, J.; Bioresour. Technol. 2013, 135, 422.

22. Cruz, J. C.; Castro, A. M.; Camporese Sérvulo, E. F.; 3 Biotech. 2018 $8,138$.

23. Jing Y.; Hao Xu, J. J.; Jiang, J.; Zhang, N.; Xie, J.; Wei, M.; Zhao, J.; J. Bioresour. Bioprod. 2019, 4, 135.

24. Wierckx, N.; Agrimi, G.; Lübeck, P. S.; Steiger, M. G.; Mira, N. P.; Punt, P. J.; Environ. Biotechnol. 2020, 62, 153.

25. Voll, A.; Klement, T.; Gerhards, G.; Buechs, J.; Marquardt, W.; Chem. Eng. Trans. 2012, 27, 367.

26. Trivedi, J.; Bhonsle, A. K.; Atray, N. Refining Biomass Residues for Sustainable Energy and Bioproducts 2020.

27. Kirimura, K.; Yoshioka, I.; Compr. Biotechnol. 2011, 3, 166.

28. Troiano, D.; Orsat, V.; Dumont, M. J.; Renewable Sustainable Energy Rev. 2020, 117, 109472.

29. https://www.wrcbtv.com/story/41571213/itaconic-acid-market-trend2020-by-manufactures-types-applications-regions-and-forecast-to-2026, acessada em junho de 2020.

30. Carvalho, J.C.; Magalhães, A.; Soccol, C.; Chim. Oggi 2018, 36, 56.

31. https://markets.businessinsider.com/news/stocks/global-itaconic-acidia-industry-1029119853, acessada em junho de 2020.

32. https://www.openpr.com/news/1910970/exhaustive-study-on-itaconicacid-market-2020-strategic, acessada em junho de 2020.
33. https://www.reportsanddata.com/report-detail/itaconic-acid-market, acessada em junho de 2020.

34. Magalhães, A. I. J.; Carvalho, J. C.; Thoms, J. F.; Medina, J. D. C.; Soccol, C. R.; J. Cleaner Prod. 2019, 206, 336

35. Huang, X.; Chen, M.; Lu, X.; Li, Y.; Li, X.; Li, J. J.; Microb. Cell Fact. 2014, 13, 108

36. Zhao, M.; Lu, X.; Zong, H.; Li, J.; Zhuge, B. I.; Biotechnol. Lett. 2018 , $40,455$.

37. Karaffa, L.; Kubicek, C. P.; Appl. Microbiol. Biotechnol. 2019, 103, 2889.

38. Cordes, T.; Lucas, A.; Divakaruni, A. S.; Murphy, A. N.; Cabrales, P.; Metallo, C. M.; Mol. Metab. 2020, 32, 122.

39. Martínez-Reynes, I.; Chandel, N. S.; Nat. Commun. 2020, 11, 102.

40. Ryan, D. G.; O’Neill, L. A. J.; Annu. Rev. Immunol. 2020, 38, 289.

41. Boruta, T.; Bizukojc, M.; World J. Microbiol. Biotechnol. 2017, 33, 34.

42. Komáromy, P.; Bakonyi, P.; Kucska, A.; Tóth, G.; Gubicza, L.; BélafiBakó, K.; Nemestóthy, N.; Fermentation 2019, 5, 31.

43. Nelson, G. E. N.; Traufler, D. H.; Kelley, S. E.; Lockwood, L. B.; Ind. Eng. Chem. 1952, 44, 1166.

44. Larsen, H.; Eimhjellen, K. E.; Biochem. J. 1955, 6217, 135.

45. Saha, B. C.; Kennedy, G. J.; J. Microbiol. Methods 2018, 144, 53.

46. Molnár, Á. P.; Németh, Z.; Kolláth, I.S.; Fekete, E.; Flipphi, M.; Ág, N.; Soós, Á.; Kovács, B.; Sándor, E.; Kubicek, C. P.; Karaffa, L.; Appl. Microbiol. Biotechnol. 2018, 102, 8799.

47. Nemestóthy, N.; Bakonyi, P.; Komáromy, P.; Bélafi-Bakó, K.; Biotechnol. Lett. 2019, 41, 1383.

48. Pfeifer, V. P.; Vojnovich. C.; Heger, E. N.; Ind. Eng. Chem. 1952, 44, 2975.

49. Songserm, P.; Thitiprasert, S.; Tolieng, V.; Piluk, J.; Tanasupawat, S.; Assabumrungrat, S.; Yang, S-T.; Karnchanatat, A.; Thongchul, N.; Appl. Microbiol. Biotechnol. 2015, 177, 595.

50. Karrafa, L.; Díaz, R.; Papp, B.; Fekete, E.; Sándor, E.; Kubicek, C. P. A.; Appl. Microbiol. Biotechnol. 2015, 99, 7937.

51. Saha, B. C.; Kennedy, G. J.; Biocatal. Agric. Biotechnol. 2019, 18, 101016.

52. Liu, Y.; Liu, G.; Zhang, J.; Balan, V.; Bao, J.; Biomass Conv. Bioref. 2020, 10, 463.

53. Yahiro, K.; Shibata, S.; Jia, S.; Park, Y. Okabe, M.; J. Ferment. Bioeng. 1997, 84, 375.

54. Pedroso, G. B.; Montipó, S.; Mario, D. A. N.; Alves, S. H.; Martins, A. F.; Biomass Convers. Biorefin. 2017, 7, 23.

55. Bafana, R.; Sivanesan, S.; Pandey, R. A.; Indian J. Microbiol. 2017, 57, 322.

56. Reddy, C. S. K.; Singh, R. P.; Bioresour. Technol. 2002, 85, 69.

57. Saha, B. C.; Kennedy, G. J.; Qureshi, N.; Bowman, M. J.; Biotechnol. Prog. 2017, 33, 1059 .

58. Kuenz, A.; Gallenmüller, Y.; Willke, T.; Vorlop, K.-D.; Appl. Microbiol. Biotechnol. 2012, 96, 1209

59. Hevekerl, A.; Kuenz, A.; Vorlop, K. D.; J. Microbiol. Biotechnol. 2014, 98, 10005.

60. Krull, S.; Eidt, L.; Heverkerl, A.; Kuenz, A.; Prüße, U.; Process Biochem. (Oxford, U. K.) 2017, 63, 169.

61. Krull, S.; Hevekerl, A.; Kuenz, A.; Prüße, U.; Appl. Microbiol. Biotechnol. 2017, 101, 4063.

62. Kreyenschulte, D.; Heyman, B.; Eggert, A.; Maßmann, T.; Kalvelage, C.; Kossack, R.; Regestein, L.; Jupke, A.; Büchs, J.; Biochem. Eng. J. 2018, 135, 133

63. Tevž. G.; Bencina, M.; Legiša, M.; Appl. Microbiol. Biotechnol. 2010, 87, 1657.

64. Rao, D. M.; Hussain, S. M. D. J.; Rangadu, V. P.; Subramanyam, K.; Krishna, G. S.; Swamy, A.V. N.; Afr. J. Biotechnol. 2007, 6, 2140.

65. El-Imam, A. M. A.; Kazeem, M. O.; Odebisi, M. B.; Mushaffa, A. O.; Abidoye, A. O.; Not. Sci. Biol. 2013, 5, 57. 
66. Vassilev, N.; Medina, A.; Eichler-Löbermann B, Flor-Peregrín, E.; Vassilev, M.; Appl. Biochem. Biotechnol. 2012, 168, 1311.

67. Hossain, A. H.; Li, A.; Brickwedde, A.; Wilms, L.; Carpers M.; Overkamp, K.; Punt, P. J.; Microb. Cell Fact. 2016, 15, 130.

68. Li, A. Pfelzer, N.; Zuijderwijk, R.; Punt, P.; BMC Biotechnol. 2012, 12, 57.

69. Yin, X.; Shin, H.; Li, J.; Du, G.; Liu, L.; Chen, J.; Appl. Environ. Microbiol. 2017, 83, 57.

70. Hossain, A. H.; Beek, A. T.; Punt, P. J.; Fungal Biol. Biotechnol. 2019, 6,1 .

71. Van Der Straat, L.; Tamayo-ramos, J.A.; Schonewille, T.; Graaff, L. H.; AMB Express 2013, 3, 1.

72. Van der Straat, L.; Vernooij, M.; Lammers, M.; Van Den Berg, W.; Schonewille, T.; Cordewener, J.; Van der Meer, I.; Koops, A.; De Graaff, L. H.; Microb. Cell Fact. 2014, 13, 11.

73. Carstensen F.; Klement T.; Buchs J.; Bioresour. Technol. 2013,137, 179.

74. Becker, J.; Tehrani, H. H.; Gauert, M.; Mampel, J.; Blanck, L. M.; Wierckx, N.; Microb. Biotechnol. 2020, 13, 350

75. Tehrani, H. H.; Becker, J.; Bator, I.; Saur, K.; Meyer, S.; Lóia, A C. R.; Blank, L. M.; Wierckx, N.; Biotechnol. Biofuels 2019, 12, 263.

76. Geiser E., Reindl, M.; Blank, L. M.; Feldbrügge, M., Wierckx, N, Schipper K.; Appl. Environ. Microbiol. 2016, 82, 5174.

77. Zambanini, T.; Hosseinpour, H. T.; Geiser, E.; Merker, D.; Schleese, S.; Krabbe, J.; Buescher, J. M.; Meurer, G.; Wierckx, N.; Blank, L. M.; Biotechnol. Biofuels 2017, 10, 131.
78. Okamoto S, Chin T.; Hiratsuka, K.; Aso, Y.; Tanaka, Y.; Takahashi, T.; Ohora, H.; J. Gen. Appl. Microbiol. 2014, 60, 191.

79. Harder, B. J.; Bettenbrock, K.; Klamt, S.; Metab. Eng. 2016, 38, 29.

80. Tran, K. N. T.; Somasundaram, S.; Eom, G. T.; Hong, S. H.; Biotechnol. Prog. 2019, 35, 1.

81. Noh, M. H.; Lim, H. G.; Woo, S. H.; Song, J.; Jung, G. Y.; Biotechnol. Bioeng. 2017, 115, 729.

82. Levinson, W. E; Kurtzman, C. P.; Kuo, T. M.; Enzyme Microb. Technol. 2006, 39, 824 .

83. Blumhoff, M. L.; Steiger, M. G.; Mattanovich, D.; Metab. Eng. 2013, 19, 26.

84. Arcaño, Y. D.; García, O. D. V.; Mandelli, D.; Carvalho, W. A.; Pontes, L. A. M.; Catal. Today 2018, 333, 100.

85. Dragone, G.; Kerssemakers, A. A. J.; Driessen, J. L. S. P.; Yamakawa, C. K.; Brumano, L. P.; Mussatto, S. I.; Bioresour. Technol. 2020, 302, 122847.

86. Yahiro, K.; Takahama, T.; Jai, S.; Park, Y.; Okabe, M.; Biotechnol. Lett. 1997, 19, 619.

87. Okabe, M.; Lies, D.; Kanamansa, S.; Park, E. Y.; Appl. Microbiol. Biotechnol. 2009, 84, 597.

88. Zhao, C.; Cui, Z.; Zhao, X.; Zhang, J.; Zhang, L.; Tian, Y.; Qi, Q.; Liu, J.; Appl. Microbiol. Biotechnol. 2019, 103, 2181.

89. Zhu, H.; Nienow, A. W.; Bujalski, W.; Simmons, M. J. H.; Chem. Eng. Res. Des. 2009, 87, 307.

90. Nunes, R. M. S.; Dissertação de Mestrado, Universidade do Minho, Portugal, 2013. 